\title{
Morphometric Variations between Susceptible and Resistant Population of Helicoverpa armigera (Hubner) Hardwick in Pigeonpea from the Different Locations of Middle Gujarat
}

\author{
V.R. Parmar ${ }^{1 *}$ and C.C. Patel ${ }^{2}$ \\ ${ }^{1}$ Office of Deputy Director of Agriculture (Extn.), Room No. 315, 3rd Floor, \\ Sardar Bhavan, Nadiad, India \\ ${ }^{2}$ Department of Agricultural Entomology, B. A. College of Agriculture Anand Agricultural \\ University, Anand-388001, Gujarat, India \\ *Corresponding author
}

\section{A B S T R A C T}

\section{Keywords \\ Helicoverpa armigera, Middle Gujarat, Morphometric variation, Pigeonpea, Resistant population, Susceptible population \\ Article Info \\ Accepted: \\ 20 August 2018 \\ Available Online: \\ 10 September 2018}

\begin{abstract}
Investigation was carried out at Entomology Department, B. A. College of Agriculture, Anand Agricultural University, Anand on variations in morphometric traits of susceptible and resistant populations of pigeonpea pod borer, Helicoverpa armigera (Hubner) Hardwick collected from different districts viz., Anand, Ahmedabad, Dahod and Vadodara of middle Gujarat studied during the year 2015-16 and 2016-17 The result showed that the larval and pupal, lengths and weights of $H$. armigera were significantly more in case of Vadodara and Ahmedabad district populations as compared to Anand and Dahod district populations as well as laboratory reared susceptible strain. The lengths of the femur and tibia for each leg as well as lengths and widths of both wings of Vadodara, Ahmedabad, Anand and Dahod district populations were found slightly more than the adults of susceptible strain.
\end{abstract}

\section{Introduction}

Pigeonpea [Cajanus cajan (L.) Millspaugh] is one of the major pulse crops of the tropics and subtropics. It is the second most important pulse crop of India after chickpea (Nene et al., 1990). Widespread occurrence of resistance to different insecticides is a serious threat to manage the $H$. armigera. The pest collected from different locations of Gujarat was found to be resistant to a wide range of insecticides viz., triazophos, endosulfan, cypermethrin, quinalphos, chlorpyriphos, fenvalerate and carbaryl (Patel and Koshiya, 1999; Patel et al., 2000 and Borad et al., 2001). Due to its wide host range, multiple generations per year, high fecundity, migratory behavior, adaptation to different environments, ability to undergo diapauses and pronounced resistance to many insecticides, the control upto desired level has become difficult (McCaffery et al., 1998). Number of factors viz., indiscriminate use of insecticides, continuous use of single group insecticides, over dosing, mixing of different insecticides of various groups, sub lethal dose, improper applications etc. are responsible for 
the development of resistance to insecticides by Helicoverpa. Based on these reasons, the present study was undertaken to demonstrate the insecticidal resistance and morphometric variations among $H$. armigera collected from different locations of middle Gujarat.

\section{Materials and Methods}

The data on area, intensity and host crops grown were collected from different four districts viz., Anand, Vadodara, Dahod and Ahmedabad (2 villages/location and 2 fields/village) of middle Gujarat. Morphometric variations of larvae, pupae and adults were recorded in all the field collected populations during 2015-16 and 2016-17. For the purpose, district wise collected larvae of $H$. armigera were reared in the laboratory and data were recorded in a subsequent generation $\left(\mathrm{F}_{1}\right)$. To study the larval morphometric characters viz., colour, length and weight of hundred larvae per location were taken. General body colours of larval stage were recorded by visual observation. Length of fifth instar larvae were measured by using centimetre scale while micro balance was used for recording weight. Pupal length and weight were recorded for 50 randomly selected pupae of $H$. armigera from each location. Pupal length $(\mathrm{mm})$ and weight $(\mathrm{mg})$ were measured by centimetre scale and micro balance, respectively. Adult traits i.e., wing characters [length $(\mathrm{mm}) \&$ width of fore wing and hind wing $(\mathrm{mm})$ ] and leg segments [length of femur and tibia $(\mathrm{mm})$ of each pair of leg] of $H$. armigera were also measured by observing 25 adults/location. For the purpose, stereoscopic microscope having software "Magnus-Pro" was used for recording measurements.

\section{Results and Discussion}

To find out the variations in morphometric characters of susceptible and resistant population, various morphometric traits of $H$. armigera were recorded at different stages (larval, pupal and adult) during the lifecycle. For the study, population of four different locations viz., Anand, Ahmedabad, Dahod and Vadodara districts were collected and studied during 2015-16 and 2016-17.

\section{Larval traits}

The results obtained on larval morphology are presented and discussed hereunder.

\section{Colour}

Different body colour morphs viz., greenish brown, dark green, light green, greenish, reddish brown, yellowish brown, blackish brown etc. were encountered in the field populations of pod borer, $H$. armigera across all sampling locations. General larval colour in $H$. armigera is supposed to be a variable trait. According to Yamasaki et al., (2009), larval coloration was determined by the portion of the plant upon which larvae were reared. Shah (2014) reported that larvae collected from Surendranagar and Sabarkantha districts exhibited dark brown body colour while that of less resistance population of Anand and Amreli population found to be pale greenish brown colour and sap green colour was observed in case of susceptible strain of $S$. litura.

\section{Length}

In the present study, the body length of $H$. armigera larvae (Table 1) was found significantly more $(29.68+2.44 \mathrm{~mm})$ in case of Vadodara and Ahmedabad populations $(29.26+2.63 \mathrm{~mm})$ as compared to population of rest of the locations. The larval size of Anand district population was comparatively small i.e. $26.30+2.29 \mathrm{~mm}$ body length followed by larval length of Dahod (23.76 + $2.38 \mathrm{~mm}$ ) district population. Larval lengths of laboratory reared susceptible strain were 
significantly smaller $(21.04+2.16 \mathrm{~mm})$ than all other field populations collected from middle Gujarat.

\section{Weight}

The data on larval weight presented in Table 1 revealed that all field collected populations of middle Gujarat had significantly more larval weight ( 454.52 to $475.60 \mathrm{mg}$ ) than the larval weight of susceptible population $(412.70 \mathrm{mg})$. Chronologically, larval weights of all field populations and susceptible strain were: Vadodara $(475.60+19.73 \mathrm{mg})>$ Ahmedabad $(467.28+27.97 \mathrm{mg})>$ Anand $(461.24+22.19$ $\mathrm{mg})>$ Dahod $(454.52+27.60 \mathrm{mg})>$ Susceptible $(412.70+19.11 \mathrm{mg})$. Larval weight of Vadodara population was found significantly more than rest of the populations which was at par with Ahmedabad population. However, larval weight of Ahmedabad population was again at par with Anand population. Further, larval weight of Anand population was at par with Dahod population. Larval weight of susceptible strain was significantly lower $(412.70+19.11 \mathrm{mg})$ than rest of the field populations.

Variations in various morphometric traits of different $H$. armigera might be due to the development of resistance against different group of insecticides. The present findings are in conformity with the findings of Fakrudin et al., (2004) in which they reported significant correlation $(r=0.9855)$ with larval length of $H$. armigera population collected from two different areas of cotton cultivation. Further, same scientists also reported positive but nonsignificant correlation in case of larval weight $(\mathrm{r}=$ 0.5938). Study on the relationship between larval resistance to different insecticides and morphometry of $H$. armigera population revealed positive and significant relationship in most of the cases with some exceptions (Vijaykumar, 2005). Higher phenotypic attributes in terms of higher larval and pupal length and weight might have strengthened the body physiology with increased enzymatic activity enabling larvae to tolerate higher dose of insecticide. According to Shah (2014), the body lengths of $S$. litura larvae were found significantly more in case of Surendranagar $(36.29+2.10 \mathrm{~mm})$ and Sabarkantha populations $(36.02+2.34$ $\mathrm{mm})$ than larval lengths of Anand and Amreli districts population while larval lengths of laboratory reared susceptible strain $(30.47+$ $5.67 \mathrm{~mm}$ ) were significantly smaller than all other field populations collected from Gujarat. Further, the data on larval weight revealed that larval weights of Surendranagar population $(1331.42+44.55 \mathrm{mg})$ was found significantly more than rest of the populations but it was at par with the weights of Sabarkantha (1325.13 $+51.13 \mathrm{mg}$ ) population while larval weights of Anand $(1316.12+52.00 \mathrm{mg})$ and Amreli $(1314.59+60.45 \mathrm{mg})$ populations were not differing significantly from each other but it were more than laboratory reared susceptible strain $(1279.96+50.26 \mathrm{mg})$.

\section{Pupal traits}

\section{Length}

The data (Table 1 and Plate 1) on pupal length of $H$. armigera collected from different locations of middle Gujarat showed same trend as observed in case of larval length. The pupal length (mm) of $H$. armigera of different middle Gujarat locations were found in the order of Vadodara $(17.80+1.95 \mathrm{~mm})>$ Ahmedabad $(17.44+1.78 \mathrm{~mm})>$ Anand $(16.46+1.92 \mathrm{~mm})>$ Dahod $(16.06+1.53$ $\mathrm{mm})>$ Susceptible $(15.10+0.91 \mathrm{~mm})$.

In the present study, the pupal lengths of $H$. armigera were found significantly more $(17.80+1.95 \mathrm{~mm})$ in Vadodara and Ahmedabad populations $(17.44+1.78 \mathrm{~mm})$ as compared to rest of locations of middle Gujarat. The pupal lengths of population 
collected from Anand $(16.46+1.92 \mathrm{~mm})$ and Dahod $(16.06+1.53 \mathrm{~mm})$ districts were almost equal and not differing significantly from each other. While, pupal lengths of susceptible strain were significantly smaller $(15.10+0.91 \mathrm{~mm})$ than rest of field populations.

\section{Weight}

The pupal weights (Table 1) of $H$. armigera were found significantly more in Vadodara $(257.22+32.56 \mathrm{mg})$ and Ahmedabad populations $(251.22+25.28 \mathrm{mg})$ and were at par with each other. However, pupal weight of Ahmedabad population was again at par with Anand $(242.26+29.91 \mathrm{mg})$ population. The pupal weights of Dahod population $(229.50+$ $24.46 \mathrm{mg}$ ) were significantly lower than the population of Vadodara, Ahmedabad and Anand districts.

Pupal weights of laboratory reared susceptible population were significantly lower $(206.64+$ $24.38 \mathrm{mg}$ ) than all the field populations. The variations in pupal weight might be due to development of resistance against different group of insecticides by various populations.

Findings related to the pupal traits of present investigation are in close agreement with the results of Fakrudin et al., (2004) wherein they found that the cotton boll worm, $H$. armigera pupa had positive and significant correlation ( $\mathrm{r}$ $=0.9255^{*}$ ) with pupal weight while positive but non-significant correlation with pupal length $(r=0.7615)$ in cypermethrin resistance population (Fakrudin et al., 2007). According to Shah (2014), the pupal lengths of S. litura were found significantly more in Surendranagar $(17.04+1.00 \mathrm{~mm})$ and Sabarkantha $(16.92+0.79 \mathrm{~mm})$ populations as compared to rest of locations of Gujarat as the Surendranagar population had developed higher resistance as compared to other populations. The pupal lengths of population collected from Anand $(16.28+1.12 \mathrm{~mm})$ and Amreli $(16.12+1.34 \mathrm{~mm})$ districts were almost equal and not differing significantly from each other. While, pupal lengths of susceptible strain $(15.55+1.01 \mathrm{~mm})$ were significantly smaller than rest of field populations. The data on pupal weights of $S$. litura were found significantly more in Surendranagar $(380.02+26.25 \mathrm{mg})$ and Sabarkantha $(378.45+23.57 \mathrm{mg})$ populations and were at par with each other. The pupal weights of Anand $(369.95+15.56 \mathrm{mg})$ and Amreli $(367.86+15.53 \mathrm{mg})$ populations were significantly lower than the pupal weights of Surendranagar and Sabarkantha populations and both were at par with each other while pupal weights of laboratory reared susceptible population $(359.34+2.47 \mathrm{mg})$ were significantly lower than all the field populations.

\section{Adult traits}

To find out morphometric variations in the adult of $H$. armigera collected from different locations of Middle Gujarat, the length of the femur and tibia for each leg as well as length and width of both wings were measured.

\section{Leg}

Looking to the data, size of the leg segments (femur and tibia) of the $H$. armigera adults was bigger (Table 2 and Plate 2) in the field collected populations than the susceptible strain.

\section{Fore leg}

In the present study, the lengths of fore femur were found significantly more $(3.25+0.20$ $\mathrm{mm}$ ) in Vadodara and Ahmedabad populations $(3.23+0.10 \mathrm{~mm})$ as compared to rest of locations of middle Gujarat and were at par with each other. The lengths of femur were significantly at par with each other for the 
adults of Anand $(3.10+0.09 \mathrm{~mm})$ and Dahod leg femur lengths of all field populations are $(3.07+0.05 \mathrm{~mm})$ districts. While, femur lengths of susceptible strain were found significantly smaller $(2.95+0.08 \mathrm{~mm})$ than all the field populations. Chronologically, fore in order of Vadodara $(3.25+0.20 \mathrm{~mm})>$ Ahmedabad $(3.23+0.10 \mathrm{~mm})>$ Anand $(3.10$ $+0.09 \mathrm{~mm})>\operatorname{Dahod}(3.07+0.05 \mathrm{~mm})>$ Susceptible $(2.95+0.08 \mathrm{~mm})$.

\begin{tabular}{|c|c|c|c|c|}
\hline \multirow[t]{2}{*}{ Locations } & \multicolumn{2}{|c|}{ Larvae } & \multicolumn{2}{|c|}{ Pupa } \\
\hline & Length (mm) & Weight (mg) & Length $(\mathrm{mm})$ & Weight (mg) \\
\hline Anand & $26.30 \pm 2.29$ & $461.24 \pm 22.19$ & $16.46 \pm 1.92$ & $242.26 \pm 29.91$ \\
\hline Ahmedabad & $29.26 \pm 2.63$ & $467.28 \pm 27.97$ & $17.44 \pm 1.78$ & $251.22 \pm 25.28$ \\
\hline Dahod & $23.76 \pm 2.38$ & $454.52 \pm 27.60$ & $16.06 \pm 1.53$ & $229.50 \pm 24.46$ \\
\hline Vadodara & $29.68 \pm 2.44$ & $475.60 \pm 19.73$ & $17.80 \pm 1.95$ & $257.22 \pm 32.56$ \\
\hline $\begin{array}{l}\text { Susceptible } \\
\text { (Laboratory } \\
\text { condition) }\end{array}$ & $21.04 \pm 2.16$ & $412.70 \pm 19.11$ & $15.10 \pm 0.91$ & $206.64 \pm 24.38$ \\
\hline S. Em. \pm & 0.34 & 3.38 & 0.24 & 3.89 \\
\hline C. D. at $5 \%$ & 0.95 & 9.38 & 0.65 & 10.79 \\
\hline C. V.\% & 9.29 & 5.27 & 10.02 & 11.59 \\
\hline
\end{tabular}

Table.3 Morphometric variations in the wings of $\boldsymbol{H}$. armigera collected from different locations of middle Gujarat (Mean \pm SD)

Locations

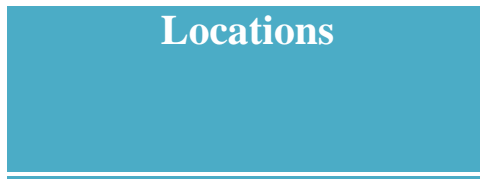

Anand

Ahmedabad

Dahod

Vadodara

Susceptible

(Laboratory condition)

S. Em. \pm

C. D. at $5 \%$

C. V.\%

\section{Length (mm)}

Fore wing

$15.70+0.25$

$15.95 \pm 0.28$

$15.54 \pm 0.45$

$16.11 \pm 0.22$

$15.27 \pm 0.36$

0.07

0.18

2.06

\section{Hind wing}

$11.44 \pm 0.66$

$11.63 \pm 0.22$

$11.32 \pm 0.59$

$12.08 \pm 0.45$

$10.86 \pm 0.50$

0.10

0.28

4.43
Width (mm)

\section{Fore wing Hind wing}

$4.56 \pm 0.36$

$5.51 \pm 0.52$

$4.68 \pm 0.38$

$5.68 \pm 0.24$

$4.51 \pm 0.43$

$5.43 \pm 0.46$

$4.71 \pm 0.27$

$5.76 \pm 0.43$

$5.22 \pm 0.18$

$4.30 \pm 0.26$

0.08

0.07

0.22

7.04 
Table.2 Morphometric variations in the legs of $\boldsymbol{H}$. armigera adults collected from different locations of middle Gujarat (Mean \pm SD)

\begin{tabular}{|c|c|c|c|c|c|c|}
\hline \multirow[t]{3}{*}{ Locations } & \multicolumn{6}{|c|}{ Length (mm) } \\
\hline & \multicolumn{2}{|c|}{ Fore leg } & \multicolumn{2}{|c|}{ Middle leg } & \multicolumn{2}{|c|}{ Hind leg } \\
\hline & Femur & Tibia & Femur & Tibia & Femur & Tibia \\
\hline Anand & $3.10 \pm 0.09$ & $3.41 \pm 0.03$ & $3.41 \pm 0.11$ & $3.32 \pm 0.03$ & $3.78 \pm 0.09$ & $3.36 \pm 0.08$ \\
\hline Ahmedabad & $3.23 \pm 0.10$ & $3.50 \pm 0.03$ & $3.48 \pm 0.06$ & $3.36 \pm 0.05$ & $4.07 \pm 0.20$ & $3.44 \pm 0.04$ \\
\hline Dahod & $3.07 \pm 0.05$ & $3.38 \pm 0.05$ & $3.40 \pm 0.06$ & $3.31 \pm 0.05$ & $3.74 \pm 0.06$ & $3.36 \pm 0.06$ \\
\hline Vadodara & $3.25 \pm 0.20$ & $3.51 \pm 0.04$ & $3.52 \pm 0.06$ & $3.38 \pm 0.05$ & $4.14 \pm 0.23$ & $3.45 \pm 0.05$ \\
\hline $\begin{array}{l}\text { Susceptible } \\
\text { (Laboratory condition) }\end{array}$ & $2.95 \pm 0.08$ & $3.28 \pm 0.06$ & $3.27 \pm 0.14$ & $3.23 \pm 0.19$ & $3.54 \pm 0.13$ & $3.26 \pm 0.17$ \\
\hline S. Em. \pm & 0.02 & 0.01 & 0.02 & 0.02 & 0.03 & 0.02 \\
\hline C. D. at $5 \%$ & 0.06 & 0.03 & 0.05 & 0.05 & 0.09 & 0.05 \\
\hline C. V. \% & 3.68 & 1.30 & 2.66 & 2.79 & 4.08 & 2.76 \\
\hline
\end{tabular}


Plate.2 Morphometric variations in the adult traits (wings and legs) of $H$. armigera collected from different Locations of middle Gujarat

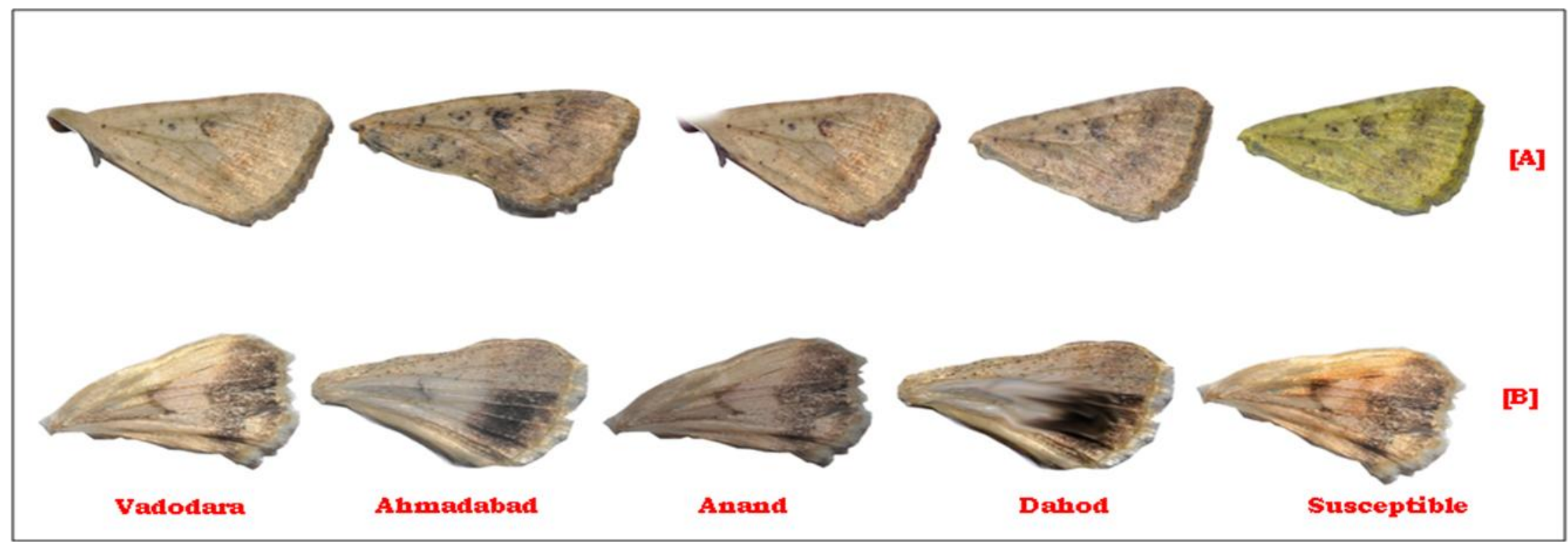

Morphometric variations in the fore $[\mathrm{A}]$ and hind [B] wings of $H$. armigera

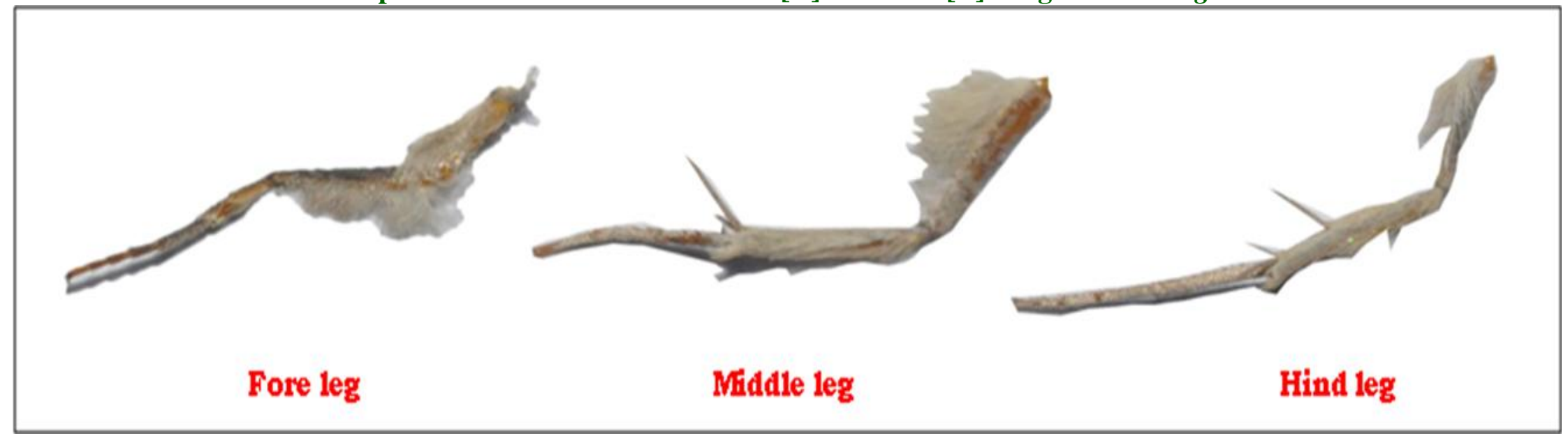


Plate.1 Morphometric variations in the pupae of $H$. armigera collected from different locations of middle Gujarat

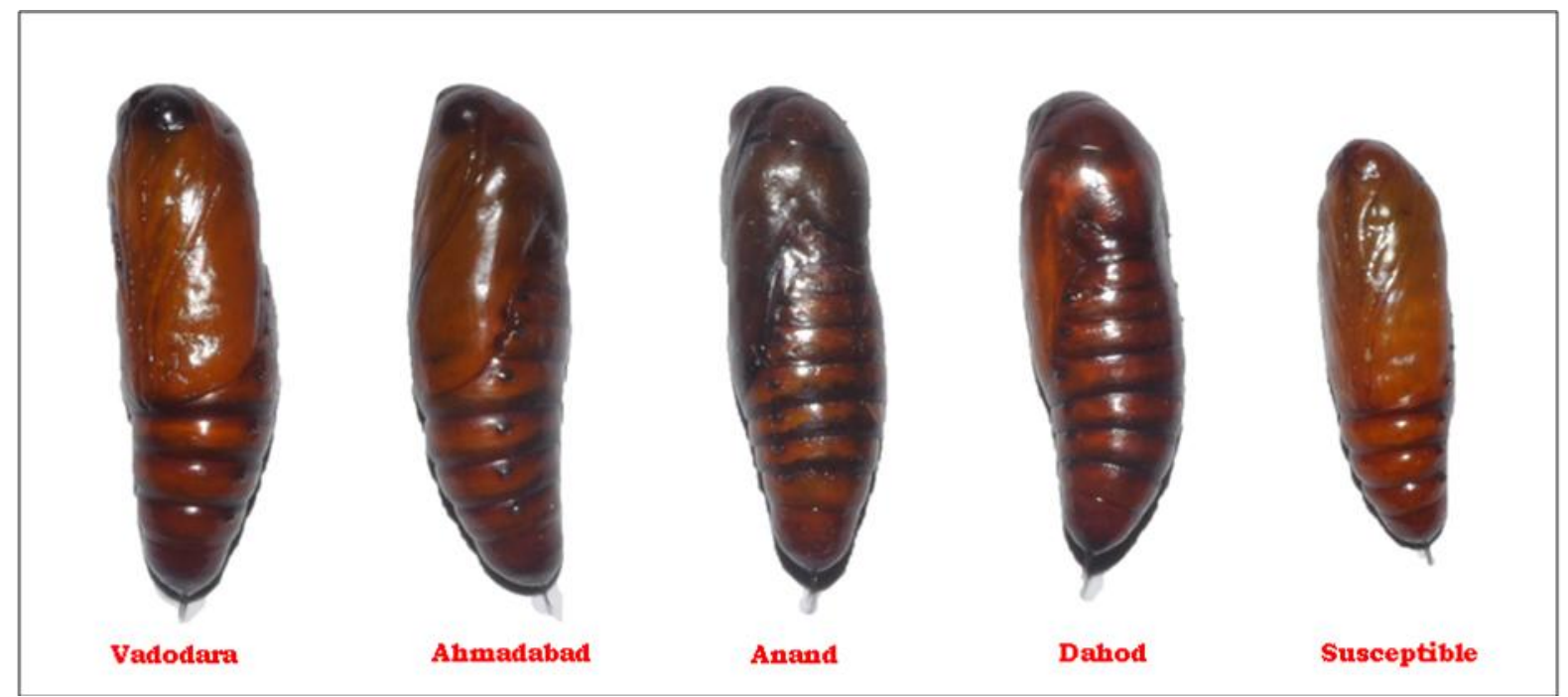

It is observed from the data (Table 2) that trend of femur lengths (fore leg) was similar to that of tibial length for the populations of all the locations of middle Gujarat. The tibial length $(\mathrm{cm})$ of $H$. armigera of different locations of middle Gujarat was found in the order of Vadodara $(3.51+0.03 \mathrm{~mm})>$ Ahmedabad $(3.50+0.04 \mathrm{~mm})>$ Anand $(3.41$ $+0.03 \mathrm{~mm})>\operatorname{Dahod}(3.38+0.05 \mathrm{~mm})>$ Susceptible $(3.28+0.06 \mathrm{~mm})$.

\section{Middle leg}

Data presented in Table 2 clearly indicated that the middle femur lengths of middle leg were significantly more in Vadodara $(3.52+$ $0.06 \mathrm{~mm})$ and Ahmedabad populations $(3.48$ $+0.06 \mathrm{~mm})$ as compared to other two locations of middle Gujarat and were at par with each other. The femur lengths of adults of Anand district were smaller i.e. $3.41+0.11$ $\mathrm{mm}$ which was at par with the femur lengths of adults of Dahod $(3.40+0.06 \mathrm{~mm})$ district. While, femur lengths of susceptible strain were found significantly smaller $(3.27+0.14$ $\mathrm{mm})$ than all the field populations. Chronologically, middle leg femur lengths of all field populations were in order of
Vadodara $(3.52+0.06 \mathrm{~mm})>$ Ahmedabad $(3.48+0.06 \mathrm{~mm})>$ Anand $(3.41+0.11 \mathrm{~mm})$ $>$ Dahod $(3.40+0.06 \mathrm{~mm})>$ Susceptible $(3.27+0.14 \mathrm{~mm})$. In the present study, significantly more tibial lengths of middle $(3.38+0.05 \mathrm{~mm})$ leg were found in Vadodara population (Table 2) which was at par with the population Ahmedabad district (3.36+ $0.05 \mathrm{~mm}$ ). However, tibial lengths of middle leg of Ahmedabad were again at par with the population Anand district $(3.32+0.03 \mathrm{~mm})$. The tibial length of middle legs of Anand district was also at par with the population of Dahod district $(3.31+0.05 \mathrm{~mm})$. While, tibial lengths of susceptible strain were found significantly smaller $(3.23+0.19 \mathrm{~mm})$ than all the field populations. The tibial length (Middle leg) of different locations of middle Gujarat were found as of Vadodara $(3.38+$ $0.06 \mathrm{~mm})>$ Ahmedabad $(3.36+0.05 \mathrm{~mm})>$ Anand $(3.32+0.03 \mathrm{~mm})>\operatorname{Dahod}(3.31+$ $0.05 \mathrm{~mm})>$ Susceptible $(3.23+0.19 \mathrm{~mm})$.

\section{Hind leg}

The femur and tibial length of hind legs were more as compared to the femur and tibial length of fore and middle legs in case of all 
the locations (Table 2). The trend for femur and tibial lengths were almost same as found in case of fore and middle legs. The femur and tibial lengths $(\mathrm{mm})$ of $H$. armigera of different locations of middle Gujarat was found as Vadodara $(4.14+0.23$ and $3.45+$ $0.05 \mathrm{~mm})>$ Ahmedabad $(4.07+0.20$ and $3.44+0.04 \mathrm{~mm})>$ Anand $(3.78+0.09$ and $3.36+0.08 \mathrm{~mm})>$ Dahod $(3.74+0.06$ and $3.36+0.06 \mathrm{~mm})>$ Susceptible $(3.54+0.13$ and $3.26+0.17 \mathrm{~mm}$ ).

In nutshell, femur and tibial lengths of adults of $H$. armigera collected from the fields of Vadodara, Ahmedabad, Anand and Dahod districts were slightly more than femur and tibial lengths of susceptible strain. Shah (2014) reported that the lengths of the femur and tibia for each leg of Surendranagar, Sabarkantha, Amreli and Anand district populations were found slightly more than the adults of susceptible strain of S. litura. While reviewing the literature, no information is available on the variation in size of legs due to development of insecticidal resistance in $H$. armigera. Hence, the present findings could not be discussed and compared with information of other research workers. So this is the first report of its kind.

\section{Wing}

The length and width of wings in case of field collected $H$. armigera population were significantly more than the length and width of the wings (fore and hind) of the adults of susceptible strain (Table 3 and Plate 2).

\section{Fore wing}

In the present study, the fore wing lengths (Table 3) of $H$. armigera were found significantly more $(16.11+0.22 \mathrm{~mm})$ in Vadodara population as compared to other locations except the population Ahmedabad district $(15.95+0.28 \mathrm{~mm})$. The fore wing lengths of the population collected from Anand were $15.70+0.25 \mathrm{~mm}$ which was followed by the population of Dahod districts $(15.54+0.45 \mathrm{~mm})$. While, fore wing lengths of susceptible strain were found significantly smaller $(15.27+0.36 \mathrm{~mm})$ than all the field populations. The fore wing length of $H$. armigera adults of different locations of Middle Gujarat was found in the order of Vadodara $(16.10+0.22 \mathrm{~mm})>$ Ahmedabad $(15.95+0.28 \mathrm{~mm})>$ Anand $(15.70+0.25$ $\mathrm{mm})>\operatorname{Dahod}(15.54+0.45 \mathrm{~mm})>$ Susceptible $(15.27+0.36 \mathrm{~mm})$.

It is observed that the width of the fore wings (Table 2) were found significantly more for the adults of Vadodara population $(4.71+$ $0.27 \mathrm{~mm}$ ) and which was at par with Ahmedabad population $(4.68+0.38 \mathrm{~mm})$ and Anand population $(4.56+0.36 \mathrm{~mm})$. However, fore wing widths of the Ahmedabad and Anand adults were again at par with the widths of Dahod $(4.51+0.43 \mathrm{~mm})$ district adults. Fore wing widths of susceptible strain were found significantly smaller $(4.30+0.26$ $\mathrm{mm}$ ) than all the field populations (Plate 2).

The fore wing widths of $H$. armigera of different locations of middle Gujarat were found in the order of Vadodara $(4.71+0.27$ $\mathrm{mm})>$ Ahmedabad $(4.68+0.38 \mathrm{~mm})>$ Anand $(4.56+0.36 \mathrm{~mm})>$ Dahod $(4.51+$ $0.43 \mathrm{~mm})>$ Susceptible $(4.30+0.26 \mathrm{~mm})$.

\section{Hind wing}

In the present study, the hind wing lengths (Table 3) of $H$. armigera were found significantly more from the adults of Vadodara population $(12.08+0.45 \mathrm{~mm})$ as compared to the other locations. The hind wing lengths of the population from Ahmedabad district were $11.63+0.22 \mathrm{~mm}$ which was at par with the population Anand district $(11.44+0.66 \mathrm{~mm})$. Hind wing lengths of the population collected from Anand were 
followed by Dahod $(11.32+0.59 \mathrm{~mm})$ populations. While, hind wing lengths of susceptible population were found significantly smaller $(10.86+0.50 \mathrm{~mm})$ than all the field populations (Plate 2). The hind wing length of $H$. armigera adults of different locations of middle Gujarat were found in the order of Vadodara $(12.08+0.45 \mathrm{~mm})>$ Ahmedabad $(11.63+0.22 \mathrm{~mm})>$ Anand $(11.44+0.66 \mathrm{~mm})>$ Dahod $(11.32+0.59$ $\mathrm{mm})>$ Susceptible $(10.86+0.50 \mathrm{~mm})$.

It is clearly observed that the widths of the hind wing (Table 3 ) were found significantly more in the adults of Vadodara population $(5.76+0.43 \mathrm{~mm})$ than the other locations except Ahmedabad population $(5.68+0.24$ $\mathrm{mm})$. However, hind wing widths of the Anand adults were $5.51+0.52 \mathrm{~mm}$ which was followed by hind wing widths of the Dahod adults $(5.43+0.46 \mathrm{~mm})$. Hind wing widths of susceptible strain were found significantly smaller $(5.22+0.18 \mathrm{~mm})$ than all the field populations. The hind wing widths of $H$. armigera of different locations of Gujarat were found in the order of Vadodara $(5.76+$ $0.43 \mathrm{~mm})>$ Ahmedabad $(5.68+0.24 \mathrm{~mm})>$ Anand $(5.51+0.52 \mathrm{~mm})>$ Dahod $(5.43+0.46$ $\mathrm{mm})>$ Susceptible $(5.22+0.18 \mathrm{~mm})$.

In general, significant impact was observed on the length/width of fore and hind wings of the $H$. armigera adults collected from Vadodara, Ahmedabad, Anand and Dahod districts and laboratory reared susceptible strain. Shah (2014) recorded the data on length/width of fore and hind wings of adults of $S$. litura collected from the fields of Surendranagar, Sabarkantha, Amreli and Anand districts were found slightly more than the adults of susceptible strain.

For the present study, $H$. armigera populations were collected from the castor fields of Vadodara, Ahmedabad, Anand and Dahod districts. Size of different stages and appendages in the population of different locations were found different. Hence, the measurement of different morphological traits were found more in case of population collected from Vadodara, Ahmedabad, Anand and Dahod as compared to laboratory reared susceptible population.

\section{References}

Borad, P. K., Patel, C. C., Patel, J. R. and Chavda, A. J. 2001. Studies on insecticide resistance in Helicoverpa armigera (Hubner) in Gujarat state. Indian J. Plant Prot. 29 (1 \& 2), 97-100.

Fakrudin, B., Vijaykumar, K. B. K., Mahaling, S. K. and Patil, B. V. 2007. Morphometric variation in geographic populations of cotton bollworm, Helicoverpa armigera (Hübner) occurring in South Indian cotton ecosystems. J. Asia-Pacific Entomol. 10 (1), 39-44.

McCaffery, A. R., Head, D. J., Jianguo, T., Dubbeldam, A. A, Subramaniam, V. R. and Callaghan, A. 1998. Nerve insensitivity resistance to pyrethroids in Heliothine lepidoptera. Pesti. Sci. 51, 315-320.

Nene, Y. L., Susan, D. H. and Sheila, V. K. 1990. The Pigeonpea. C.A.B. International, Wallingford for ICRISAT, Patancheru, India. p. 490.

Patel, C. C. and Koshiya, D. J. 1999. Insecticidal resistance to Helicoverpa armigera (Hub.) Hardwick in Gujarat. Indian J. Ent. 61 (2), 121-126.

Patel, C. C., Borad, P. K., Baloliya, K. F. and Patel, J. R. 2000. Relative resistance to conventional synthetic insecticides in Helicoverpa (Heliothis) armigera Hubner in Gujarat. Indian J. Ent. 62 (4), 358-362.

Shah, K. D. 2014. Status of insecticidal resistance, its management and morphometric studies of leaf eating 
caterpillar, Spodoptera litura Fabricius in different locations of Gujarat. Ph. D. Thesis submitted to Anand Agricultural University, Anand, Gujarat.

Vijaykumar 2005. Geographic variation in morphometry, genetics and insecticide resistance in cotton bollworm, Helicoverpa armigera (Hubner) populations occurring in South Indian cotton ecosystems and validation of
IPM and IRM modules. Ph. D. Thesis submitted to University of Agricultural Sciences, Dharwad.

Yamasaki, A., Shimizu, K. and Eujisaki, K. 2009. Effect of host plant part on larval body-colour polymorphism in Helicoverpa armigera (Lepidoptera: Noctuidae). Ann. Ent. Soc. Am. 102, 76-84.

\section{How to cite this article:}

Parmar, V.R. and Patel, C.C. 2018. Morphometric Variations between Susceptible and Resistant Population of Helicoverpa armigera (Hubner) Hardwick in Pigeonpea from the Different Locations of Middle Gujarat. Int.J.Curr.Microbiol.App.Sci. 7(09): 2865-2875. doi: https://doi.org/10.20546/ijcmas.2018.709.356 